\title{
Where there is fire, there is smoke
}

David B. Lindenmayer and Chris Taylor

Fenner School of Environment and Society, The Australian National University, Canberra, ACT,2601 David.Lindenmayer@anu.edu.au; christaylor2746@gmail.com

Warren Cornwall writes a fascinating article on wildfire-generated smoke and associated large quantities of particulate matter [1]. We agree that research on smoke demands more sustained scientific attention, particularly given its impacts on human communities (e.g. see [2]). However, not all kinds of fires are created equal in terms of their (natural or deliberate) origins, the amount of biomass consumed, and hence the amount of smoke generated.

High-intensity wildfires (e.g. those exceeding 200000 kw per m2) in very high biomass forests may consume $9-14 \%$ of the biomass or $40-58$ tonnes per hectare [3]. We calculate this is substantially less than half the 140-450 tonnes of biomass per hectare consumed when logging slash is burned after logging operations in these same kinds of forest $(4,5)$. Moreover, such logging burns consume at least 10 times more biomass than hazard reduction burns designed to reduce wildfire risk (6). Indeed, a high proportion of the smoke that blankets the Australian city of Melbourne for prolonged periods originates not from wildfires or hazard reduction burns but from burns after logging. The smoke generated from logging therefore represents a substantial form of industrial pollution, but is not treated as such. We argue that beyond improving efforts to quantify the chemical composition of smoke and its long-term impacts on human health, there is an urgent need to examine the problem holistically. This demands far more careful consideration of the origins of smoke, the relative amounts of smoke originating from different kinds of fires, and the forest and land use policies that generate smoke (and might reduce it). 
A.

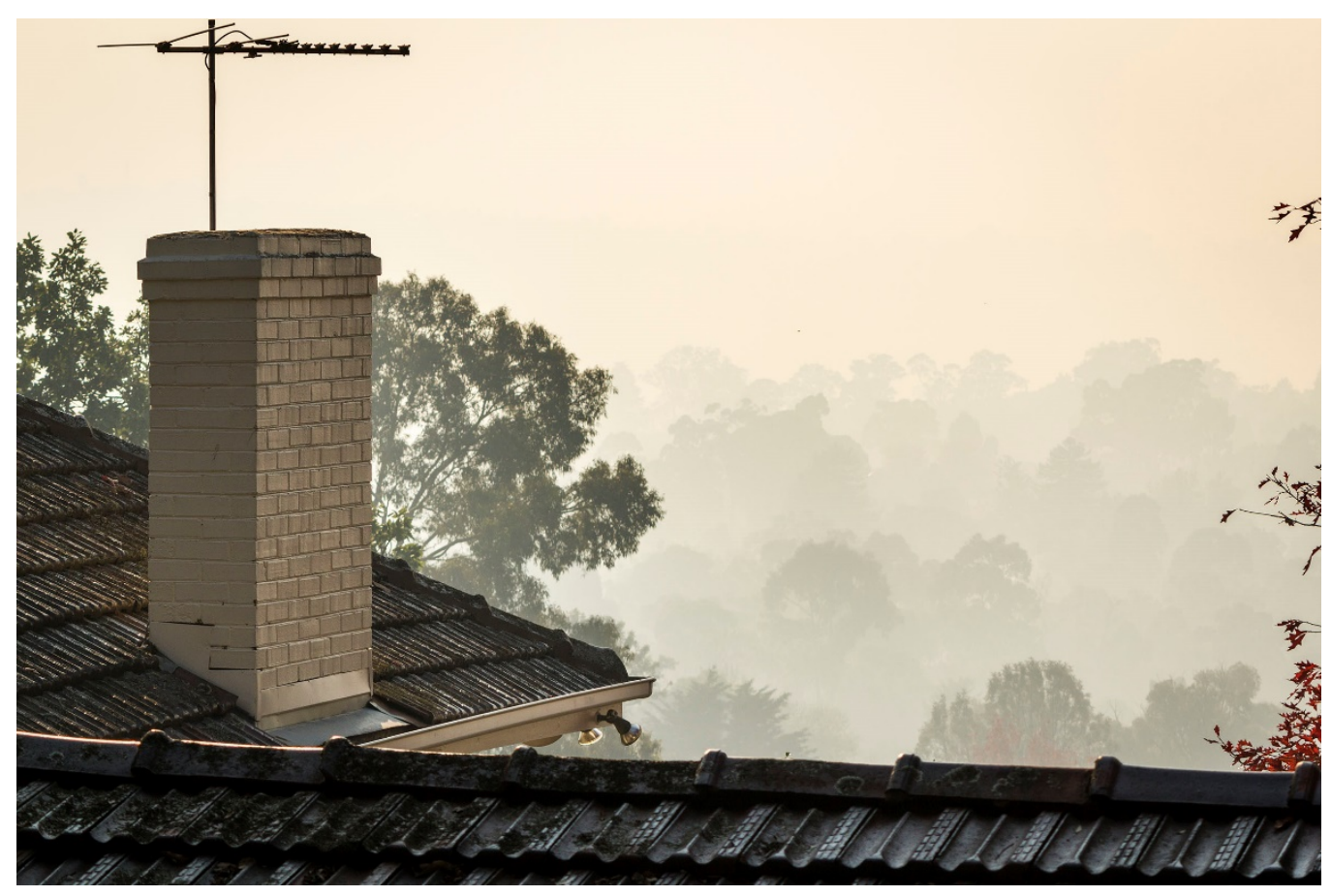

B.

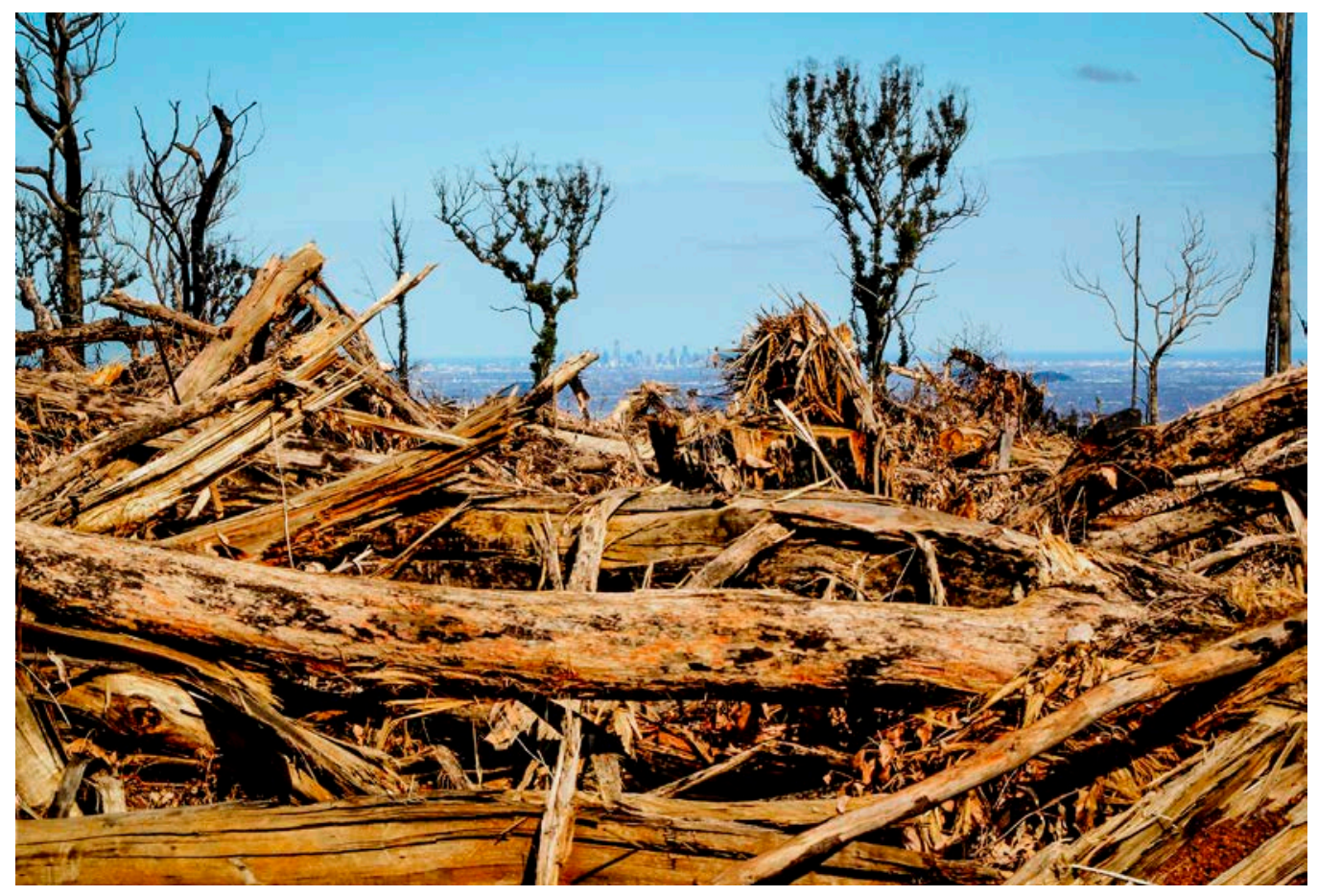




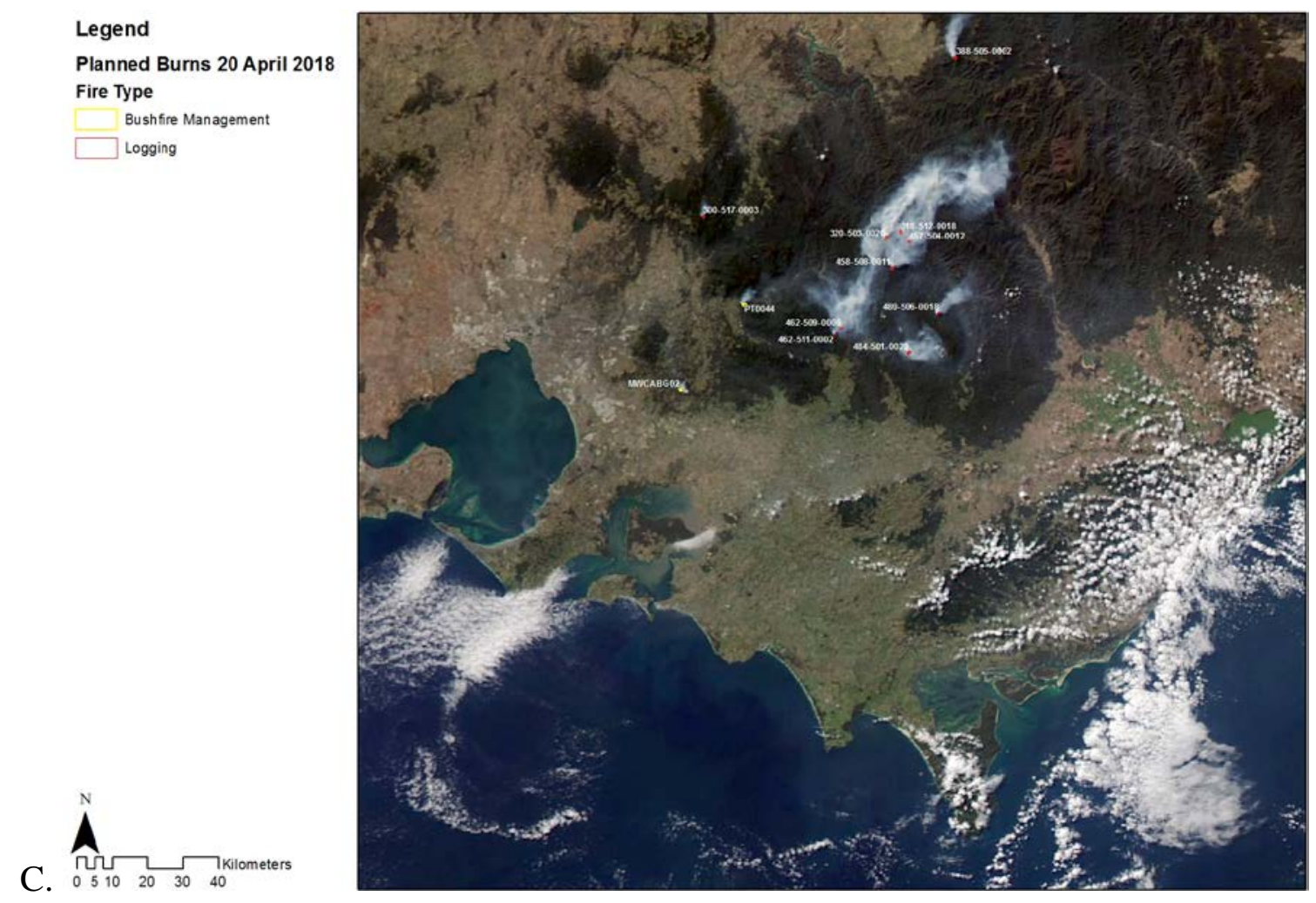

Photos: A. Smoke over Melbourne (C. Taylor). B. The Melbourne skyline from a logging coupe (C. Taylor). C. Satellite photo of logging burns in the Central Highlands (NASA).

\section{REFERENCES}

1. Cornwall, W. 2018. Scientists aim to smoke out wildfire impacts. Science, 360, 948949.

2. Cascio, W.E. 2018. Wildland fire smoke and human health. Science of the Total Environment, 624 (2018) 586-595.

3. Keith, H., Lindenmayer, D.B., Mackey, B.G., Blair, D., Carter, L., McBurney, L., Okada, S. and Konishi-Nagano, T. (2014). Accounting for biomass carbon stock change due to wildfire in temperate forest landscapes in Australia. PLOS One, 9, e107126.

4. Raison, RJ., Squire, RO. 2008, Forest Management in Australia: Implications for Carbon Budgets - Technical Report No.32, Australian Greenhouse Office.

5. Slijepcevic, A. 2001. Loss of Carbon during controlled regeneration burns in Eucalyptus obliqua forest, TasForests, Vol. 13, No.2

6. Tolhurst, KG., Cheney, NP. 1999. Synopsis of the knowledge used in prescribed burning in Victoria, Department of Natural Resources and Environment, Melbourne 